\title{
Las Modificaciones a la Ley Brasileña de Arbitraje
}

\author{
Rodolfo da Costa Manso Real Amadeo* y \\ Thomas Alexandre de Carvalho** \\ Recibido/Received: 15/12/2015 \\ Aceptado/Accepted: 19/08/2016
}

\begin{abstract}
SUMARIO: 1. Introducción. 2. El avance del sistema arbitral en Brasil bajo la Ley N. 9.307/1996. 2.1. La necesidad de reforma de la Ley de Arbitraje: aspectos prácticos. 3. La nueva Ley N. 13.129/2015. 4. Conclusiones.
\end{abstract}

PALABRAS CLAVE: arbitraje, Ley Brasileña de Arbitraje, modificaciones

KEYWORDS: amendments, arbitration, Brazilian Arbitration Act

RESUMEN: La Ley Brasileña de Arbitraje (Ley N. 9.307/1996) sufrió recientes modificaciones (Ley $\mathrm{N}$. 13.129/2015) que son o soluciones de preocupaciones antiguas de la práctica arbitral en Brasil y ya encontraban respaldo en orientaciones más o menos consagradas en la doctrina y jurisprudencia o son verdaderas innovaciones.

* Socio de la firma Lilla, Huck, Otranto, Camargo Advogados (Brasil), Profesor del Curso de Postgrado de la Escuela de Derecho de São Paulo de la Fundación Getúlio Vargas. Abogado por la Universidad de São Paulo, Master en Derecho Procesal Civil por la Universidad de São Paulo, Doctor (Ph.D.) en Derecho Procesal Civil por la Universidad de São Paulo. Árbitro.

** Socio de la firma Lilla, Huck, Otranto, Camargo Advogados (Brasil). Abogado por la Universidad de São Paulo. Master en derecho civil en curso por la Universidad de São Paulo.

R. Da Costa Manso Real y T. De Carvalho, "Las Modificaciones a la Ley Brasileña de Arbitraje", Revista Ecuatoriana de Arbitraje, No. 7, 2015. 
Este artículo traerá el lineamiento general del escenario actual del arbitraje en Brasil bajo las nuevas modificaciones.

ABSTRACT: The Brazilian Arbitration Act (Law N. 9.307/1996) has suffered some recent amendments (Law N. $13.129 / 2015)$ that provide either solutions for the brazilian arbitration practitioners' old concerns that were already found in treatise writers and judicial interpretation or represent genuine innovations. This paper will address the main modifications to the current Brazilian arbitration scenario after these amendments.

\section{INTRODUCCIÓN}

El 26 de mayo de 2015, Brasil sancionó la Ley N. 13.129/2015 con el objeto de modificar y complementar algunas disposiciones de la Ley Brasileña de Arbitraje (Ley N. 9.307/1996), aplicable tanto para arbitrajes dentro del Brasil e internacionales, y además insertó disposiciones específicas sobre arbitraje en materia societaria en la Ley Brasileña de las Sociedades por Acciones (Ley N. 6.404/1976). En su preámbulo la nueva Ley N. 13.129/2015:

“Modifica la Ley N. 9.307, del 23 de septiembre de 1996 [Ley de Arbitraje], y la Ley N. 6.404, del 15 de diciembre de 1976 [Ley de las Sociedades por Acciones], para ampliar el ámbito de aplicación del procedimiento arbitral y resolver acerca de la designación de los árbitros cuando las partes recurren a los órganos arbitrales, la interrupción de la prescripción como efecto de la institución de arbitraje, la concesión de medidas cautelares y de urgencia en arbitraje, la carta arbitral, y deroga artículos de la Ley N. 9.307, de 23 de septiembre de 1996"1.

Aunque la nueva ley ya esté en vigor desde fines de julio de 2015, las recientes modificaciones aún no fueron receptadas por completo por la doctrina brasileña -tampoco por la jurispruden-

1. Todas las referencias a los diplomas normativos brasileños fueran traducidas al español por los autores de este artículo. 
cia- de tal modo que el presente artículo traerá lineamientos generales de las modificaciones efectuadas. Algunas modificaciones todavía, son soluciones de preocupaciones antiguas de la práctica arbitral en Brasil y ya encontraban respaldo en orientaciones más o menos consagradas en la doctrina y jurisprudencia. Otras son verdaderas innovaciones. Adecuadas o no, el tiempo lo dirá. Por ahora, nuestro trabajo se limita a presentar lo que cambia con el nuevo ordenamiento legal.

\section{El aVAnCe del Sistema arbitral en Brasil bajo LA LEY N. 9.307/1996}

Antes de la sanción de la Ley N. 9.307/1996, el arbitraje en Brasil era muy poco utilizado. A causa de dos motivos: la ausencia de tratamiento de la cláusula compromisoria en el Código Civil Brasileño de 1916 y en el Código de Procedimiento Civil Brasileño de 1973 y la necesidad de someter el laudo arbitral a la homologación judicial ${ }^{2}{ }^{3}$. Así, para la institución de arbitrajes antes de la promulgación de la referida ley, no sólo era necesario que las partes expresamente pactasen el compromiso arbitral al efecto de tratar un conflicto específico, sino que también una vez finalizado el trámite del procedimiento arbitral, con el laudo final (cualquiera que fuera su naturaleza o resultado), debía ser necesariamente homologado por el Poder Judicial para que pudiera producir sus efectos ${ }^{4} \mathrm{y}$ en consecuencia, pasar por todo el trámite procesal estatal sujeto al doble control jurisdiccional y a eventuales recursos ante las cortes superiores.

2. Todas las referencias a bibliográficas en lengua extranjera fueran traducidas al español por los autores de este artículo.

3. Véase, por ejemplo, C. A. CARmona, sobre este punto: "Básicamente, eran dos los grandes obstáculos que la ley brasileña criaba para la utilización de la arbitraje: en primer, el legislador simplemente ignoraba la cláusula compromisoria (el Código Civil de 1916 y el Código de Procedimiento Civil de 1973 no tenían cualquier regla a ese respecto); adicionalmente, el diploma procesual, consonante la tradición de nuestro derecho, exigía la homologación judicial del laudo arbitral”, Arbitragem e Processo, 3ra. Ed., São Paulo: Atlas, 2009, p. 4.

4. Así era la redacción del artículo 1.097 del Código de Proceso Civil derogado por la Ley de Arbitraje. "Art. 1.097. El laudo arbitral, después de homologado, produce entre las partes y sus sucesores los mismos efectos de la sentencia judiciaria; contiendo condenación de la parte, la homologación conferirá eficacia de título ejecutivo (Artículo 584, III)". 
Al fin y al cabo, el procedimiento arbitral brasileño antes de la Ley de Arbitraje no era atractivo a las partes, atento a la inexistencia de obligatoriedad de las cláusulas compromisorias para las partes. Sólo después de surgido el conflicto y de que las partes lograsen elegir el arbitraje como alternativa para su solución, además debían recurrir al Poder Judicial para que se proceda a la homologación de la decisión arbitral.

Estas dificultades, sin embargo, fueron claramente superadas con la sanción de la Ley N. 9.307/1996. La Ley de Arbitraje Brasileña otorgó total eficacia a las cláusulas compromisorias insertas en el cuerpo de los contratos firmados, quedando las partes vinculadas al procedimiento arbitral y evitando la necesidad de celebrar un compromiso arbitral, y además excluyó la necesidad de homologación de los laudos arbitrales junto al Poder Judicial, equiparando los efectos de las sentencias arbitrales y judiciales ${ }^{5}$. De esta forma el procedimiento arbitral ganó autonomía. Además, la ley confirió reglas y adoptó directrices de las leyes más modernas de aquel tiempo, como la Ley Italiana, la Ley Española y la Ley Francesa.

Pero la tradición brasileña no estaba preparada para tamaño cambio de perspectivas, ya que estaba enraizado en la comunidad jurídica el rechazo a la utilización de tal procedimiento. No es exagerado decir que la utilización del arbitraje solamente logró inmiscuirse en la comunidad jurídica brasileña después del juzgamiento respecto de la constitucionalidad de la Ley $\mathrm{N}$. 9.307/1996, llevado a cabo por el Supremo Tribunal Federal del Brasil con fecha 12 de diciembre de $2001^{6}$.

Hoy en día, incluir una cláusula de compromiso arbitral en contratos de gran valor económico es práctica común e incentivada en las firmas de abogados brasileñas, no solo por la posibilidad de elegir los árbitros con conocimientos en la materia en

5. Art. 31. La sentencia produce, entre las partes y sus sucesores, los mismos efectos de la sentencia proferida por los órganos del Poder Judiciario y, siendo condenatoria, constituí título ejecutivo.

6. Véase, Supremo Tribunal Federal, Homologación de Sentencia Extranjera, Min. Sepúlveda Pertence, No. 5.206, de 12/12/2001, <www.stf.jus.br>. 
litigio, sino por la celeridad del procedimiento y la imposibilidad de apelar la sentencia arbitral, cuestiones que otorgan gran seguridad jurídica a las partes.

Hoy en día las empresas brasileñas se destacan mundialmente como grandes utilizadores del sistema de arbitraje como método alternativo de resolución de conflictos. Una publicación reciente de la International Chamber of Commerce (ICC) ubica a Brasil como el tercer país en número de arbitrajes en aquél centro, solamente detrás de EE.UU. y Francia ${ }^{7}$.

Otro dato a destacar y que corrobora la importancia que le fue conferida al arbitraje en Brasil, es el valor medio de los litigios en curso en el Centro de Mediação e Arbitragem da Câmara de Comércio Brasil-Canadá - CAM-CCBC, importante centro de arbitraje brasileño, que fue de $\mathrm{R} \$ 26.956 .271,45$ (veintiséis millones novecientos cincuenta y seis mil doscientos setenta y un reales y cuarenta y cinco centavos) para el año 2013, lo que era equivalente, en la época, a aproximadamente US\$ 11.500.000,00 8 (once millones quinientos mil dólares).

Como se puede apreciar, el escenario actual del arbitraje en Brasil es muy positivo. La Ley N. 13.129/2015 no pretendió cambiar ese escenario, más si complementarlo, corregir algunas deficiencias, y sanar dudas que eran de conocimiento de todos y cuya solución era-comúnmente- ofrecida por la jurisprudencia y doctrina.

7. ICC “2014 ICC Dispute Resolution Statistics”, ICC Dispute Resolutin Bulletin 2015 No. 1. $<$ http://goo.gl/pfhyy4> (30/12/2015).

8. CAM, Centro de Arbitragem e mediação. "Estatística: janeiro a dezembro de 2015" $<$ http://goo.gl/R13rkw> (30/12/2015). 


\subsection{La neCesidad de Reforma de la Ley de Arbitraje: ASPECTOS PRÁCTICOS}

El nuevo orden legal instituido con la Ley N. 9.307/1996 no era perfecto y algunas modificaciones y complementos se anunciaban como necesarios.

Por ejemplo, en materia de medidas cautelares, la Ley N. 9.307/1996 sólo previa la posibilidad de que las partes las solicitaran directamente al Tribunal Arbitral, sin decir nada respecto de la posibilidad de solicitárselas directamente al Poder Judicial. La ley guardaba silencio acerca de las medidas cautelares cuya necesidad de interposición fuesen antes de la constitución del tribunal arbitral. Véase lo que decía el derogado párrafo $4^{\circ}$ del artículo 22:

"Excepto lo dispuesto en el párrafo $2^{\circ}$, urgida la necesidad de medidas coercitivas o cautelares, los árbitros podrán solicitárselas al órgano del Poder Judicial que sería, originalmente, competente para juzgar la causa."

Pero la práctica demostró la existencia de varias situaciones cotidianas que necesitaban de pronunciamientos urgentes, mayormente antes de la institución del Tribunal Arbitral que, según la ley brasileña, se encontraba legalmente constituido con la aceptación de la designación del árbitro, si fuese único o por todos los árbitros, si hay más de uno9. Por ejemplo, cuando una de las partes necesitaba hacer un pago en forma judicial de parte del crédito para no caer en los efectos de la mora. Este fue uno de los puntos más criticado por muchos estudiosos del tema ${ }^{10}$.

Otro punto que necesitaba de mejor tratamiento legal era el plazo para la anulación de la sentencia arbitral parcial. La Ley N. 9.307/1996 no trataba el tema porque el artículo 33 (hoy dero-

9. Art. 19. Considera-se instituido el arbitraje cuando acepta la nominación por el árbitro, si único, o por todos, si fueren varios.

10. Véase, C. A. Carmona, Arbitragem e Processo, 3ra. Ed., São Paulo: Atlas, 2009, p. 326 y F. J. CAhAli, Curso de Arbitragem, São Paulo: RT, 2011, p. 329. 
gado), no hacia diferencia entre la sentencia parcial y final. El artículo derogado decía así,

La parte interesada podrá concurrir ante el Poder Judicial competente para solicitar la declaración de nulidad de la sentencia arbitral, en los casos previstos en esta Ley. $§ 1^{\circ}$. La demanda para anulación de la sentencia arbitral seguirá el procedimiento ordinario, previsto en el Código de Procedimiento Civil, y deberá ser solicitada en el plazo de hasta noventa días después de recibida la notificación de la sentencia o de su aditamento [...].

Es por ello que, S. LEMES dijo que "todo abogado diligente proponía la acción anulatoria en los 90 días a contar de la sentencia parcial y no final"11. Era patente la falta de seguridad jurídica en el orden legal entonces vigente: no se esperaba a la sentencia final para intentar la anulación de la sentencia parcial, aún sin previsión expresa en la ley.

Otro punto a destacar es la posibilitad de someter a la administración pública a un procedimiento arbitral. El tema fue demasiado obscuro en la Ley N. 9.307/1996, que solo preveía que los únicos litigios susceptibles de acceder a la vía arbitral debían ser aquellos en los que participasen personas con capacidad y cuyo objeto fuese de orden patrimonial disponible. C. A. CARMONA ya decía,

La arbitrabilidad de las causas que involucran -directa o indirectamente- al Estado es materia que suscita aún hoy vivo debate. A pesar de que haya un importante (y vetusto) precedente representado por el caso testigo "Lage", según el cual el Supremo Tribunal Federal estableció que no es posible impedir someter una cuestión que pueda ser objeto de transacción a la solución arbitral ${ }^{12}$.

En efecto, la cuestión era polémica, pero no impidió que contratos con la Administración Pública fuesen redactados con cláu-

11. "Entrevista-Professora Selma Lemes", Revista de Arbitragem e Mediação, v. 46/2015, p. 448.

12. C. A. Carmona, Arbitragem e Processo, Atlas, 2009, p. 45. 
sula sometiendo los litigios oriundos de aquél contrato a la solución arbitral, como pasó a ser expresamente permitido en algunas leyes brasileñas, por ejemplo, la Ley del Petróleo y Gas (Ley N. 9.478/1997), la Ley de Aparcería Público-Privada (Ley N. 11.079/2004), la Ley N. 11.196/2005, que modificó la Ley de Concesiones Públicas (Ley N. 8.987/1995) para autorizar la utilización del arbitraje, y tantas otras leyes en igual sentido.

La interrupción de la prescripción en materia de arbitraje tampoco era pacífica. El Código Procesal Civil establece que la interrupción de la prescripción ocurre con la notificación fehaciente. ¿En el arbitraje, cómo será? La Ley 9.307/1996 no brindaba respuesta, y la doctrina oscilaba, algunos defendiendo que la interrupción solamente se producía cuando se acepta la designación de los árbitros y la instauración de arbitraje ${ }^{13}$.

El artículo 25 de la Ley de Arbitraje también creaba situaciones que daban lugar a inequidades ${ }^{14}$, pues las partes podían, con mala fe, introducir controversias con contenido de derechos indisponibles para alcanzar la suspensión del arbitraje hasta la decisión -definitiva- de estas controversias ante el Poder Judicial.

Solamente se presentaron cinco ejemplos prácticos de temas en que la Ley N. 9.307/1996 necesitaba ser mejorada. Sabedor de estas dificultades prácticas que aparecían cotidianamente a los operadores del derecho, el legislador sancionó la Ley N. 13.129/2015 que, según S. LEMES, ha traído modificaciones en tres órdenes,

“La primera, referida a lo que ya estaba previsto en la jurisprudencia; la segunda es innovadora, porque trae nuevas disposiciones; la tercera es supresora, porque retira una disposición impropia de la ley que es el art. 25, así como adapta las modificaciones en el nuevo texto"15.

13. Véase, F. J. CAhali, Curso de Arbitragem, São Paulo: RT, 2011, p. 221.

14. Art. 25 Sobrevendo en el curso del arbitraje controversia acerca de derechos indisponibles y verificando-sé que de su existencia -o no-dependerá el juzgamiento, el árbitro o el tribunal arbitral remeterá las partes a la autoridad competente del Poder Judiciario, suspendiendo el procedimiento arbitral. Párrafo único. Resulta la cuestión prejudicial y juntada a los autos la sentencia o decreto, tendrá el normal seguimiento el arbitraje.

15. “Entrevista-Professora Selma LemeS", Revista de Arbitragem e Mediação, v. 46/2015, p. 447. 
Rodolfo da Costa Manso Real Amadeo y

Thomas Alexandre de Carvalho

Las modificaciones efectuadas por la Ley N. 13.129/2015 serán objeto del título que sigue.

\section{LA Nueva Ley N. 13.129/2015}

El norte seguido por el legislador brasileño en las modificaciones a la Ley de Arbitraje puede ser extraído de la exposición de motivos de la Ley N. 13.129/2015, que dice:

"Pasados más de 17 años desde su sanción, la Ley de Arbitraje se encontró con un avance significativo de nuevas tecnologías, profundas modificaciones legislativas en el campo procesal y la jurisprudencia que viene pronunciándose favorablemente en torno del instituto, lo que hizo nacer la necesidad de su perfeccionamiento. Además, las experiencias positivas obtenidas con la utilización del arbitraje recomiendan su aplicación a otras formas de relaciones jurídicas, contribuyendo a la reducción de demandas en el Poder Judicial, en cuanto otorga una perspectiva de racionalidad para la jurisdicción estatal, hoy sobrecargada con el abultado volumen de procesos. Al efecto de optimizar la Ley de Arbitraje y ponerla a tono con el escenario internacional, Brasil realizó modificaciones puntuales que no afectaran su estructura normativa principal"16.

Las modificaciones impulsadas por la Ley N. 13.129/2015 serán explicadas según el orden en que fueron introducidas en la redacción de la Ley de Arbitraje, con su numeración ahora vigente.

En el artículo primero, fueron adicionados dos párrafos con la intención de aclarar cualquier duda acerca de la posibilidad de utilizar la vía arbitral por la Administración Pública. A continuación la nueva redacción del artículo primero:

16. "Lei 13.129, de 26 de maio de 2015: íntegra da Reforma à Lei de Arbitragem, vetos, exposição de motivos, relatório da Comissão de Juristas e pareces da Comissão de Constituição e Justiça", Revista de Arbitragem e Mediação, v. 46, 2015, pp. 29-54. 
“Art. $1^{\circ}$ Las personas con capacidad de contratar podrán utilizar la vía arbitral para dirimir litigios relativos a derechos patrimoniales disponibles.

$\S 1^{\circ} \mathrm{La}$ administración directa e indirecta podrá valerse de la vía arbitral para dirimir conflictos relativos a derechos disponibles.

$\S 2^{\circ}$ La autoridad u órgano competente de la administración pública directa para la celebración de la convención de arbitraje es la misma para la realización de acuerdos y transacciones."

Aún acerca de la utilización de la vía arbitral para la solución de litigios con la Administración Pública, fue introducido el párrafo tercero en el artículo segundo, prohibiendo el sigilo y la equidad como forma juzgamiento del conflicto envolviendo el Estado, in verbis, "el arbitraje que involucre a la administración pública será siempre de derecho y respetará el principio de publicidad". Ciertamente, las dudas que orbitaban acerca de la materia fueran aclaradas con la nueva redacción de los artículos primero y segundo de la Ley N. 9.307/1996. A mayor abundamiento, en el mismo año de 2015, fue dictado el Decreto N. $8.465 / 2015$, reglamentando los criterios para la realización de arbitrajes que involucren a la Administración Pública brasileña y empresas del sector portuario.

El Poder Legislativo intentó introducir, en los párrafos tercero y cuarto del artículo cuarto de la Ley, la posibilidad de someter a la vía arbitral conflictos del derecho laboral y reglamentar acabadamente la posibilidad de solución de conflictos agregando el derecho del consumidor. Pero la iniciativa no fue exitosa, porque las disposiciones fueron vetadas por el presidente de la república en ejercicio.

Se dio nueva redacción al párrafo cuarto del artículo trece, a fin de evitar que se limite la libertad de las partes a la indicación de las reglamentaciones de los árbitros (dadas en los centros de arbitraje), práctica común en los principales centros brasileños; de acuerdo al texto que sigue, 
"§ $4^{\circ}$ Las partes, de común acuerdo, podrán dejar de lado la aplicación de las disposiciones del reglamento del centro arbitral o entidad especializada que limite la designación del árbitro único, o demás árbitros o presidente a la respectiva lista de árbitros, autorizado el control de la designación por los centros competentes, aunque, en los casos de impase o arbitraje multiparte, deberá ser observado lo que indique el reglamento aplicable."

En el artículo 19, una pequeña modificación en el escrito del párrafo único, que sufrió nueva numeración y pasó a ser el párrafo primero y, se creó el párrafo segundo, con la indicación -precisa y taxativa- que in fine establece: "[...] $2^{\circ}$ la institución del arbitraje interrumpe la prescripción, regresando a la fecha del requerimiento de la demanda arbitral $[\ldots]^{\prime \prime}$.

Asimismo se crearon los artículos 22-A y 22-B que representó un cambio ya receptado por la jurisprudencia y doctrina imperantes acerca de las cautelares. Los artículos reglaron la posibilidad expresa para que las partes acudan al Poder Judicial a efectos de obtener medidas cautelares o urgentes antes de la institución de la demanda arbitral, cabiendo al árbitro la posibilidad de derogarlas o modificarlas, los artículos mencionados dicen:

Art. 22-A. Antes de instituido el arbitraje, las partes podrán solicitar al Poder Judicial la concesión de medida cautelar o de urgencia.

Párrafo único. Cesa la eficacia de la medida cautelar o de urgencia si la parte interesada no presenta el requerimiento en el plazo de 30 (treinta) días, contado de la fecha de adoptada la decisión.

Art. 22-B. Instituido el arbitraje, cabrá a los árbitros mantener, modificar o revocar la medida cautelar o de urgencia concedida por el Poder Judicial. Párrafo único. Ya instituido el arbitraje, la medida cautelar o de urgencia será solicitada directamente a los árbitros. 
Ante la falta de un mecanismo adecuado en la ley para realizar la comunicación entre el Tribunal Arbitral y el Poder Judicial, fue creada la figura de la carta arbitral, según la cual:

Art. 22-C. El árbitro o el tribunal arbitral podrán expedir carta arbitral para que el órgano jurisdiccional nacional practique o determine el cumplimiento, en el área de su competencia territorial, del acto solicitado por el árbitro. Párrafo único. En el cumplimiento de la carta arbitral será observado el secreto de justicia, desde que sea comprobada la confidencialidad estipulada en el arbitraje.

El artículo veintitrés discurre acerca de la sentencia arbitral. El cambio que merece atención estuvo en la creación de párrafo esclareciendo la posibilidad de los árbitros en dictar sentencias parciales, lo que ya era permitido por algunos reglamentos de los centros arbitrales brasileños y se llevaba a cabo en la práctica.

La Ley N. 13.129/2015 dio nueva redacción al artículo treinta y tres que trata de la nulidad de las sentencias arbitrales. El párrafo primero del artículo terminó con la duda existente acerca del plazo para la anulación de sentencia parcial y final, indicando que son plazos distintos, cada cual con su respectivo término inicial a contar desde la notificación de la parte. El párrafo segundo inauguró la posibilidad de la sentencia judicial que juzgue sobre la procedencia de la acción anulatoria de la sentencia arbitral podrá determinar que el tribunal arbitral profiera nueva sentencia en cambio de la sentencia recurrida. El párrafo cuarto, a su vez, establece la posibilidad de la sentencia, en la acción anulatoria, que permite al árbitro establecer una sentencia complementaria, si la sentencia atacada no decidía sobre todos los pedidos sometidos a su jurisdicción. A continuación los párrafos primero, segundo y cuarto, respectivamente,

$\S 1^{\circ}$. La demanda para declaración de nulidad de sentencia arbitral, parcial o final, seguirá las reglas del procedimiento común, previstas en la Ley N. 5.869/1973 (Código de Proceso Civil), y deberá ser propuesta en el plazo de hasta 90 (no- 
venta) días después de recibida la notificación de la respectiva sentencia, parcial o final, o de la decisión del pedido de aclaratoria.

$\S 2^{\circ}$. La sentencia que juzgue procedente el pedido declarará la nulidad de la sentencia arbitral, en los casos del art. 32, y determinará, si fuera necesario, que el árbitro dicte una nueva sentencia arbitral. [...]

$\S 4^{\circ}$. La parte interesada podrá solicitar al Poder Judicial se expida sobre la necesidad de dictar una sentencia complementaria, si el árbitro no decidiese sobre todos los pedidos sometidos al arbitraje.

Finalmente, la Ley N. 13.129/2015 modificó la Ley de Sociedades por Acciones (Ley N. 6.404/1976), con la creación del artículo 136-A,

Art. 136-A. La aprobación de inserción de la convención de arbitraje en el estatuto social, respetando el quorum del artículo 136, obliga a todos los accionistas, asegurando al accionista disidente el derecho de retirarse de la compañía mediante el reembolso del valor de sus acciones, en los términos del artículo 45 .

$\S 1^{\circ}$ La convención solamente tendrá eficacia después de transcurrido el plazo de 30 (treinta) días, contado de la publicación del acta de la asamblea general que la aprobó.

$\S 2^{\circ}$ El derecho de receso previsto no será aplicable: I - En caso de que la inclusión de la convención en el estatuto social represente condición para que los valores mobiliarios de la emisión de la compañía sean admitidos a la negociación en el seguimiento de lista de bolsa de valores o de mercado de balcão organizado que exija dispersión accionaria mínima de $25 \%$ de las acciones de cada especie o clase; II - En caso de que la inclusión de la convención de arbitraje sea efectuada en el estatuto social de compañía abierta cuyas acciones sean dotadas de liquidez y dispersión en el mercado, en los términos de los incisos ' $a$ ' y ' $b$ ' del inciso II del artículo 137 de esta ley.

Ese cambio fue importante para reglamentar la solución de conflictos en materia societaria, que revelaba grandes discusiones sobre el alcance de la convención de arbitraje a socios no signata- 
rios del acuerdo de accionistas o mismo de la posibilidad del socio a retirarse de la sociedad al momento de incluir la cláusula de arbitraje en el estatuto social.

\section{Conclusiones}

De acuerdo a lo expuesto en el presente trabajo, la Ley N. 13.129/2015 ha traído importantes cambios a la Ley Brasileña de Arbitraje, incentivando y facilitando su uso en conflictos involucrando a la Administración Pública, reglando mejor su posibilidad de utilización en litigios entre socios de sociedades de acciones y solucionando algunos problemas prácticos que la creciente utilización del arbitraje demostró en el país. El nuevo ordenamiento legal se muestra propicio en cuanto al desarrollo del arbitraje ya sea interna o internacionalmente. 